\title{
Course of Improvement in Depressive Symptoms to a Single Intravenous Infusion of Ketamine vs Add-on Riluzole: Results from a 4-Week, Double-Blind, Placebo-Controlled Study
}

\author{
Lobna Ibrahim', Nancy DiazGranados',2, Jose Franco-Chaves', Nancy Brutsche', loline D Henter ${ }^{3}$, \\ Phillip Kronstein ${ }^{1,4}$, Ruin Moaddel ${ }^{5}$, Irving Wainer ${ }^{5}$, David A Luckenbaugh', Husseini K Manji ${ }^{6}$ and \\ Carlos A Zarate Jr*,I
}

'Experimental Therapeutics and Pathophysiology Branch, Division of Intramural Research Programs, National Institute of Mental Health (NIMH), National Institutes of Health (NIH), Bethesda, MD, USA; ${ }^{2}$ University of Texas Health Science Center, San Antonio, TX, USA; ${ }^{3}$ Molecular Imaging Branch, NIMH, NIH, Bethesda, MD, USA; ${ }^{U}$ US Food and Drug Administration, Silver Spring, MD, USA; ${ }^{5}$ National Institute of Aging, NIH, Bethesda, MD, USA; ${ }^{6}$ Johnson and Johnson Pharmaceutical Research and Development, Titusville, NJ, USA

\begin{abstract}
The N-methyl-D-aspartate antagonist ketamine has rapid antidepressant effects in patients with treatment-resistant major depression (TRD); these effects have been reported to last for I week in some patients. However, the extent and duration of this antidepressant effect over longer periods has not been well characterized under controlled conditions. Riluzole, a glutamatergic modulator with antidepressant and synaptic plasticity-enhancing effects, could conceivably be used to promote the antidepressant effects of ketamine. This study sought to determine the extent and time course of antidepressant improvement to a single-ketamine infusion over 4 weeks, comparing the addition of riluzole vs placebo after the infusion. Forty-two subjects (18-65) with TRD and a Montgomery-Asberg Depression Rating Scale (MADRS) score of $\geqslant 22$ received a single intravenous infusion of ketamine $(0.5 \mathrm{mg} / \mathrm{kg})$. Four to six hours postinfusion, subjects were randomized to double-blind treatment with either riluzole $(100-200 \mathrm{mg} /$ day; $n=2 \mathrm{I}$ ) or placebo $(n=2 \mathrm{I})$ for 4 weeks. Depressive symptoms were rated daily. A significant improvement $(P<0.001)$ in MADRS scores from baseline was found. The effect size of improvement with ketamine was initially large and remained moderate throughout the 28-day trial. Overall, $27 \%$ of ketamine responders had not relapsed by 4 weeks following a single ketamine infusion. The average time to relapse was I 3.2 days $(\mathrm{SE}=2.2)$. However, the difference between the riluzole and placebo treatment groups was not significant, suggesting that the combination of riluzole with ketamine treatment did not significantly alter the course of antidepressant response to ketamine alone. Neuropsychopharmacology (2012) 37, I526-I533; doi:I0.1038/npp.20 II.338; published online I February 2012
\end{abstract}

Keywords: antidepressant; depression; glutamate; ketamine; NMDA; riluzole

\section{INTRODUCTION}

A major limitation associated with all existing antidepressant medications is their lag of onset of action. These medications can take weeks to months to achieve their full effects, leaving patients vulnerable to devastating symptoms and elevated risk of self-harm (Machado-Vieira et al, 2008). Considerable clinical and preclinical evidence suggests that drugs that modulate the glutamatergic system, especially at

*Correspondence: Dr CA Zarate, Jr., Experimental Therapeutics and Pathophysiology Branch, National Institute of Mental Health (NIMH), National Institutes of Health $(\mathrm{NIH}), 10 \mathrm{Ctr}$ Dr, CRC, Unit 7 Southeast, Room 7-3445, Bethesda, Maryland, 20892, USA, Tel: (30I) 45I-086I, Fax: (30I) 402-9360, E-mail: zaratec@mail.nih.gov

Received 9 September 2011; revised 7 December 201 I; accepted 19 December 2011 the $N$-methyl-D-aspartate (NMDA) receptor (NMDAR) complex, result in rapid onset of antidepressant response (aan het Rot et al, 2010; Berman et al, 2000; Diazgranados et al, 2010a; Diazgranados et al, 2010b; Preskorn et al, 2008; Valentine et al, 2011; Zarate et al, 2006). A single infusion of the NMDA antagonist ketamine given to patients with treatment-resistant depression (TRD) was associated with an improvement in depressive symptoms lasting well beyond its half-life (Berman et al, 2000; Diazgranados et al, 2010a; Diazgranados et al, 2010b; Zarate et al, 2006). Although variable, the duration of antidepressant effects appeared to be approximately 1 week in some patients (Zarate et al, 2006). Other uncontrolled studies suggested that the antidepressant effects of ketamine might last for several weeks or more (reviewed in Zarate et al, 2010). It is important to note that for TRD patients, even 
a partial improvement that does not meet more formal response or remission criteria may nevertheless be meaningful and have a major impact on their ability to function. Thus, a more precise understanding of the extent and duration of antidepressant improvement with a single infusion of ketamine is crucial for future treatment and research efforts.

Despite the psychotomimetic and dissociative side effects of ketamine, considerable enthusiasm exists regarding its development as a possible treatment for patients with TRD. Among the strategies under consideration are the administration of repeated doses of ketamine or augmentation with other drugs that are better tolerated than ketamine; the latter strategy would permit the administration of a singleketamine infusion followed by treatments that do not induce psychotomimetic effects, with the goal of obtaining a rapid and sustained antidepressant effect.

The antidepressant effects of ketamine are believed to result from increased presynaptic glutamate release with the net effect of enhanced glutamatergic throughput at the 2-amino-3-(5-methyl-3-oxo-1,2-oxazol-4-yl) propanoic acid (AMPA) receptor (AMPAR) relative to the NMDAR (Maeng et al, 2008). Preclinical work demonstrated that the antidepressant-like effects of ketamine were selectively averted when an AMPAR antagonist was given immediately prior to ketamine (Maeng and Zarate, 2007; Maeng et al, 2008). This suggests that the effects of ketamine occur principally through AMPAR activation, inducing rapid AMPARmediated synaptic potentiation (Sanacora et al, 2008). Additional evidence supporting the effects of ketamine on synaptic plasticity includes the finding that ketamine rapidly activates the mammalian target of the rapamycin (mTOR) signaling pathway, resulting in rapid and sustained elevation of synapse-associated proteins and spine number in the prefrontal cortex of rats (Li et al, 2010).

Given the delayed mechanism of action of currently available antidepressants, any pharmacological strategy that could exert rapid and sustained antidepressant effects within hours or even days would have a profound impact on patients' quality of life as well as public health. Thus, one reasonable strategy for optimizing the rapid antidepressant effects of ketamine and minimizing its side effect profile would be to provide a single dose of ketamine, immediately followed by another glutamatergic modulator with synapticpotentiating properties but without psychotomimetic effects. In this regard, a series of studies found that riluzole, an inhibitor of glutamate release with anticonvulsant and neuroprotective properties, possessed antidepressant properties in animal models of depression as well as in TRD patients and may affect synaptic potentiation (Du et al, 2007; Sanacora et al, 2007; Zarate et al, 2004). For instance, chronic administration of riluzole increased synaptic AMPAR subunit 1 (GluR1) ( $\mathrm{Du}$ et al, 2007). This suggests the possibility of maintaining the AMPAR throughput achieved with ketamine by using riluzole; hypothetically, rapid onset of action could be achieved by ketamine and then sustained by riluzole, which would concomitantly avoid the dissociative effects associated with chronic treatment with ketamine. We postulated that directly targeting NMDARs and enhancing AMPAR throughput with ketamine, followed immediately by riluzole treatment, would further promote the antidepressant effects achieved with ketamine in TRD patients. Preliminary clinical experience for such a strategy comes from a study of 14 TRD patients who met response criteria $72 \mathrm{~h}$ after ketamine administration and were randomized to a 4-week, doubleblind, controlled trial with riluzole or placebo (Mathew et al, 2010). An interim analysis showed no significant difference in time-to-relapse between groups.

Here we report the results of a single-center, inpatient, randomized, double-blind, 4-week, placebo-controlled trial with riluzole or placebo in patients with TRD who received a single ketamine infusion. The objectives of this study were to determine the extent and time course of antidepressant improvement to a single intravenous dose of ketamine in patients with TRD, and to determine whether the addition of riluzole would have an additional benefit in improving depressive symptoms. Partial results from the pre-randomization phase were previously published (Diazgranados et al, 2010b).

\section{MATERIALS AND METHODS}

\section{Patient Selection}

Subjects were recruited from physician referrals throughout the United States and from local inpatient psychiatric units, as well as through advertisements in local newspapers and on the internet. Men and women aged 18-65 years were eligible to participate if they had a diagnosis of recurrent major depressive disorder without psychotic features, as diagnosed using the Structured Clinical Interview for Axis I DSM-IV Disorders-Patient Version (First et al, 2001). Patients with a history of antidepressant- or substanceinduced hypomania or mania were excluded. All subjects were studied at the Clinical Research Center (CRC) of the National Institute of Mental Health (NIMH) in Bethesda, Maryland between January 2006 and September 2010. Subjects were required to have a score of $\geqslant 22$ on the Montgomery-Asberg Depression Rating Scale (MADRS) at screening and on the day of ketamine infusion (baseline), with no greater than a $25 \%$ decrease in MADRS total score between these two time points. Furthermore, patients had to have previously failed at least two adequate antidepressant trials, and currently be experiencing a major depressive episode of at least 4 weeks duration (adequacy of antidepressant trials was determined using the modified antidepressant treatment history form (Sackeim, 2001)).

All subjects were in good physical health as determined by medical history, physical examination, blood labs, electrocardiogram (ECG), chest X-ray, urinalysis, and toxicology screen. Subjects were free of comorbid substance abuse or dependence (excluding nicotine or caffeine) for at least 3 months and had a negative urine toxic screen on admission. Comorbid axis I anxiety disorder diagnoses were permitted if they were not the primary focus of treatment within 12 months before screening. Exclusion criteria included any serious unstable medical disorder or condition, previous use of ketamine, riluzole, phencyclidine, or concomitant treatment with psychotropic medications or ECT in the 2 weeks prior to ketamine infusion (5 weeks for fluoxetine); in addition, female subjects could not be pregnant or nursing. 
The study was approved by the Combined Neuroscience Institutional Review Board of the National Institutes of Health (NIH). All subjects provided written informed consent before entry into the study and were assigned a clinical research advocate from the NIMH Human Subjects Protection Unit to monitor the consent process and research participation throughout the study.

\section{Sample Size}

The study was designed to detect a moderate to large difference $(d=0.70)$. between ketamine plus riluzole $v s$ ketamine plus placebo, so a minimum of 34 patients were expected per group to achieve $80 \%$ power with $P<0.05$, two-tailed. However, the protocol stipulated an interim analysis after approximately $60 \%$ of the data were collected to check safety measures and efficacy assumptions. The results of that interim analysis $(n=42)$ are reported here.

\section{Study Design and Medications}

This was a double-blind, randomized, parallel, placebocontrolled, flexible-dose inpatient study conducted to assess two measures: first, the efficacy and safety of the addition of riluzole to ketamine compared with ketamine alone; and second, the time course of antidepressant response to a single intravenous dose of the NMDA antagonist ketamine. Following a 2-week drug-free period, 42 subjects with TRD currently experiencing a major depressive episode without psychotic features received a single open-label infusion of $0.5 \mathrm{mg} / \mathrm{kg}$ of ketamine hydrochloride (Abbott Labs, North Chicago, IL) over 40 min via a Baxter infusion pump by an anesthesiologist in the peri-anesthesia care unit. Ketamine dose was based on previous studies of patients with mood disorders (Berman et al, 2000; Diazgranados et al, 2010a; Diazgranados et al, 2010b; Zarate et al, 2006). Four to six hours post-infusion, patients were randomized in a doubleblind manner to receive either riluzole or placebo for 4 weeks. All study investigators, staff, and patients were blind to riluzole or placebo assignment. For patients in the ketamine-riluzole group, the dose of riluzole was initiated and maintained at $100 \mathrm{mg} / \mathrm{day}$ (50 mg b.i.d.). During weekly evaluations, this dose could be flexibly increased in increments of $50 \mathrm{mg}$ to a maximum of $200 \mathrm{mg} /$ day. Dose escalations continued on a weekly basis until the appearance of treatment-limiting side effects or completion of the study. Dose reductions were permitted by one capsule $(50 \mathrm{mg})$ in case of side effects. Subjects who were unable to tolerate the lowest dose of riluzole allowable $(100 \mathrm{mg} /$ day $)$ were discontinued from the study. Treatment compliance was monitored by capsule counts and by the nurses who administered the study medication. No additional medications that primarily affect the central nervous system were allowed during the study.

Patients were hospitalized at the CRC of the NIMH-NIH for the duration of the study. Vital signs, digital oximetry, and ECG were monitored during the ketamine infusion as well as for one hour post-infusion. Complete blood counts, electrolyte panels, and liver function tests were obtained at baseline and at weeks 2 and 4, or at study exit. ECGs were obtained at baseline and at the end of the study.

\section{Main Outcome Measures}

Subjects were rated $60 \mathrm{~min}$ prior to ketamine infusion, at 40 , 80,120 , and 230 min post-infusion, and then daily for the next 28 days following the infusion. Rating scales included the MADRS (Montgomery and Asberg, 1979), which was the primary outcome measure. Secondary measures were the 17-item Hamilton Rating Scale for Depression (HAM-D) (Hamilton, 1960), the self-administered Beck Depression Inventory (BDI) (Beck and Beamesderfer, 1974), the visual analogue scale for depression (VAS-depression) (Aitken, 1969), the Hamilton Anxiety Rating Scale (HAM-A) (Hamilton, 1959), the Brief Psychiatric Rating Scale (BPRS)-positive symptoms (Overall and Gorham, 1962), the Clinician Administered Dissociative States Scale (CADSS) (Bremner et al, 1998), the Young Mania Rating Scale (YMRS) (Young et al, 1978), and the Scale for Suicide Ideation (SSI) (Beck et al, 1979). The HAM-A was obtained at baseline, $230 \mathrm{~min}$, and on days 1, 3, 7, 14, 21, and 28 . Patient ratings were performed by research nurses, a physician, and a psychologist who trained together to establish reliability. High inter-rater reliability was obtained for the MADRS (intraclass correlation coefficient (ICC) = $0.94)$, HAM-D $(\mathrm{ICC}=0.92)$, and YMRS $(\mathrm{ICC}=0.92)$. Throughout the study, the same rater conducted most ratings for an individual patient.

\section{Ketamine and Norketamine Plasma Levels}

Ketamine and norketamine plasma levels were obtained at 40 and 80 min post-infusion (see Supplementary Methods).

\section{Statistical Analyses}

Linear mixed models with restricted maximum likelihood estimation were used to examine the change in clinical ratings over the course of the study. Study day was a withinsubjects factor and treatment group was a between-subjects factor; the interaction between day and treatment group was included. Schwarz's Bayesian criteria were used to determine the best-fitting variance-covariance structure, an autoregressive moving average model. The fixed intercept was included, but the random intercept and random subject effect were not because they did not contribute significantly to the model. Post-hoc tests were simple effects tests with Bonferroni correction.

The primary analysis used the intent-to-treat sample where all participants had at least one post-baseline measure. The primary outcome measure was the MADRS, so Hochberg's adjusted Bonferroni procedure was applied only to secondary measures. Raw $P$-values are reported. Cohen's $d$ was calculated comparing the treatment groups at various time points to understand the size of differences; positive values indicate lower ratings in the ketamineriluzole group. Additional analyses were performed using only patients who responded to ketamine at $230 \mathrm{~min}$ or before to understand whether riluzole might extend the initial response to ketamine. Kaplan-Maier survival analysis was performed using a log rank test to examine time to relapse in each treatment group. Response was considered a $50 \%$ improvement from baseline on the MADRS. Response was counted as a single time point reaching criteria. All 
participants meeting response criteria on or before $230 \mathrm{~min}$ were included. Relapse was considered a $<25 \%$ improvement from baseline for at least 2 consecutive days after reaching at least $50 \%$ improvement. Time to relapse was counted from the first day of the consecutive relapse days so the minimum time to relapse was 1 day.

All analyses used two-tailed significance criteria of $P<0.05$ and were performed with IBM SPSS 19 (IBM SPSS, 2010, Chicago, IL, www.spss.com).

\section{RESULTS}

\section{Patients}

Of the 118 subjects screened, 42 met study criteria, received a single ketamine infusion, and were subsequently randomized to receive 4 weeks of either riluzole or placebo (Figure 1). Demographic and clinical characteristics are summarized in Table 1. Despite an average of 46.1 $(\mathrm{SD}=23.8)$ days in the hospital prior to ketamine infusion, MADRS scores did not change significantly from hospital entry to ketamine infusion $(t=1.03$, d.f. $=36, P=0.31$; mean change $=-0.6, \mathrm{SD}=3.4)$. In all, 21 patients were randomized to receive placebo and 21 to receive riluzole. Except for a difference in past exposure to an SSRI, no statistical differences were noted between the groups on demographic factors or baseline clinical measures (Table 1).
Patients receiving riluzole reached a maximum dose of $173.8 \mathrm{mg} /$ day $(\mathrm{SD}=43.6)$.

Overall, 67\% (14/21) of TRD patients in the ketamineriluzole group and $62 \%(13 / 21)$ of TRD patients in the ketamine-placebo group completed the study $\left(\chi^{2}=0.10\right.$, $P=0.75)$.

\section{Efficacy}

The linear mixed model showed a significant improvement in MADRS scores over time $(F=8.81$, d.f. $=28,297$, $P<0.001$ ), but the differences between treatment groups and the interaction between time and treatment group were not significant (treatment: $F=0.00$, d.f. $=1,40$, $P=0.99$; time $\times$ treatment: $\mathrm{F}=1.20, \quad$ d.f. $=28, \quad 297$, $P=0.23$ ) (Figure 2). MADRS scores were significantly lower than baseline from day 1 through day 28 for the full sample. The biggest non-significant difference between the two treatment groups was at day 4, where Cohen's $d$ was 0.35 (95\% confidence interval: $-0.12-0.82$ ), indicating lower scores in the ketamine-riluzole group.

Additional models showed similar results for all the rating scales (HAM-D (time: $\mathrm{F}=7.04$, d.f. $=28,314, P<0.001$; treatment: $\mathrm{F}=0.13$, d.f. $=1,40, P=0.72$; time $\times$ treatment: $\mathrm{F}=0.81$, d.f. $=28,314, P=0.81$; Figure 2), BDI (time: $\mathrm{F}=9.47$, d.f. $=28, \quad 232, \quad P<0.001 ;$ treatment: $\mathrm{F}=0.12$, d.f. $=1,41, P=0.74$; time $\times$ treatment: $F=1.09$, d.f. $=28$,

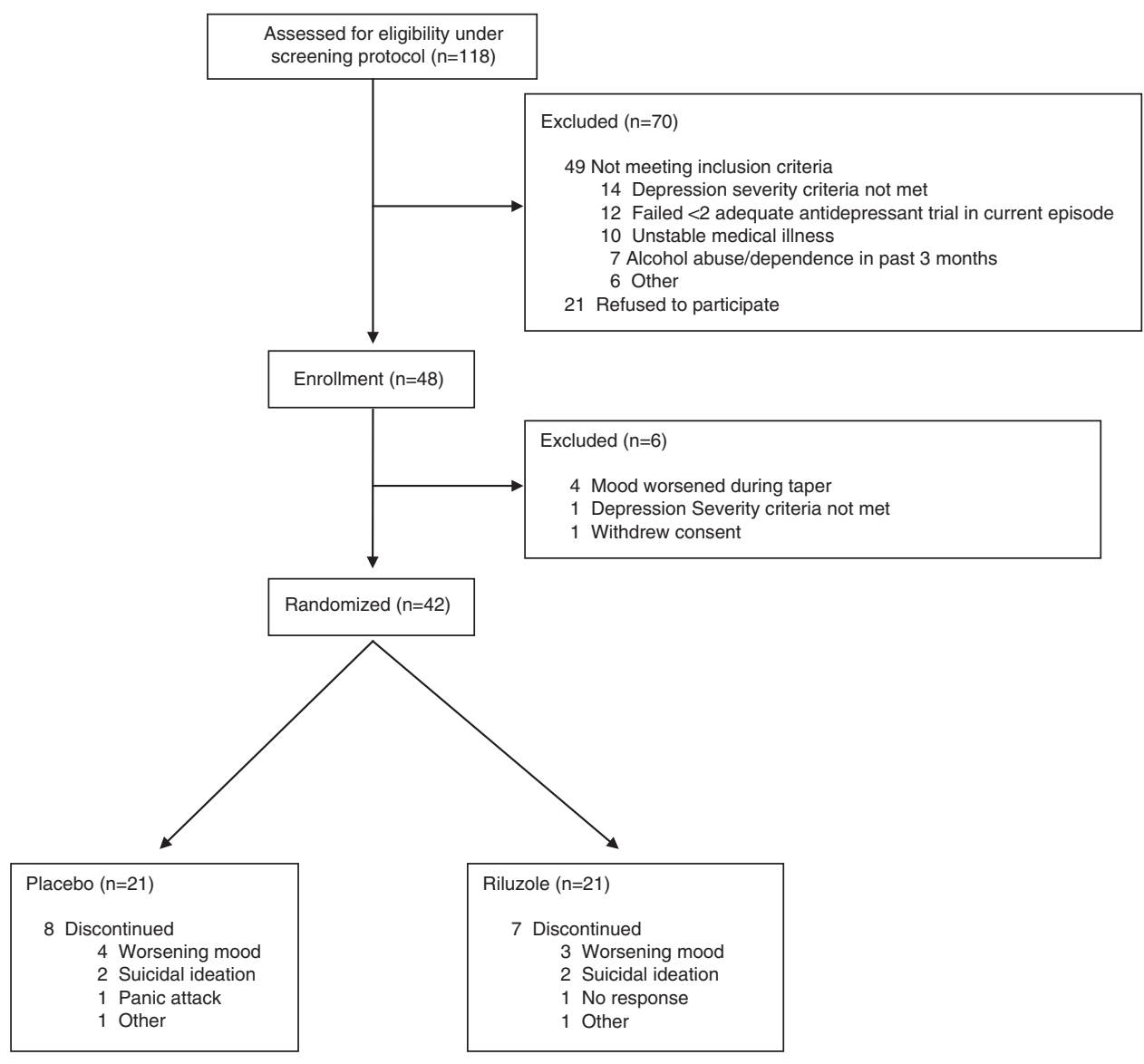

Figure I CONSORT diagram indicating patient recruitment, exclusion, and randomization. 
Table I Demographic and Illness Characteristics for Patients Receiving Ketamine and Placebo or Ketamine and Riluzole

\begin{tabular}{|c|c|c|c|c|c|c|}
\hline & \multirow{2}{*}{\multicolumn{2}{|c|}{$\begin{array}{c}\begin{array}{c}\text { Ketamine+ } \\
\text { placebo }\end{array} \\
(n=21)\end{array}$}} & \multirow{2}{*}{\multicolumn{2}{|c|}{$\begin{array}{c}\begin{array}{c}\text { Ketamine+ } \\
\text { riluzole }\end{array} \\
(n=21)\end{array}$}} & \multirow[t]{3}{*}{$\chi^{2}$} & \multirow[t]{3}{*}{$P$} \\
\hline & & & & & & \\
\hline & $n$ & $\%$ & $n$ & $\%$ & & \\
\hline Gender (female) & 8 & 38 & 8 & 38 & 0.00 & 1.00 \\
\hline Education (college) & 15 & 71 & 12 & 57 & 0.93 & 0.33 \\
\hline Disability & 9 & 43 & 12 & 57 & 1.65 & 0.20 \\
\hline Unemployed & 16 & 76 & 18 & 90 & 1.38 & 0.24 \\
\hline Lifetime alcohol abuse or dependence & 6 & 29 & 6 & 29 & 0.00 & 1.00 \\
\hline $\begin{array}{l}\text { Lifetime substance abuse or } \\
\text { dependence }\end{array}$ & 7 & 33 & 7 & 33 & 0.00 & 1.00 \\
\hline Lifetime suicidal ideation & 11 & 52 & 14 & 67 & 0.89 & 0.35 \\
\hline Anxiety disorder & 12 & 57 & 10 & 48 & 0.18 & 0.67 \\
\hline \multicolumn{7}{|l|}{ Family history } \\
\hline Mood disorder & 17 & 81 & 18 & 90 & 0.67 & 0.41 \\
\hline $\begin{array}{l}\text { Alcohol abuse or dependence } \\
\text { (first degree) }\end{array}$ & 7 & 33 & 9 & 43 & 0.82 & 0.37 \\
\hline Suicide attempt & 7 & 33 & 7 & 39 & 0.13 & 0.72 \\
\hline \multicolumn{7}{|l|}{ Past medication/somatic treatment } \\
\hline Atypical antipsychotics & 11 & 52 & 10 & 48 & 0.10 & 0.76 \\
\hline Bupropion & 16 & 76 & 16 & 76 & 0.00 & 1.00 \\
\hline ECT & 9 & 43 & 7 & 33 & 0.40 & 0.53 \\
\hline Lithium & 8 & 38 & 8 & 40 & 0.02 & 0.90 \\
\hline MAOI & 9 & 43 & 7 & 35 & 0.27 & 0.61 \\
\hline Mirtazapine & 9 & 43 & 5 & 25 & 1.45 & 0.23 \\
\hline SNRI & 19 & 90 & 14 & 67 & 3.54 & 0.06 \\
\hline SSRI & 17 & 81 & 20 & 100 & 4.22 & 0.04 \\
\hline TCA & 12 & 57 & 10 & 50 & 0.21 & 0.65 \\
\hline Abnormal liver function tests & 4 & 19 & 7 & 35 & 1.33 & 0.25 \\
\hline
\end{tabular}

Response (50\% decrease in MADRS)

$\begin{array}{lllllll}230 \mathrm{~m} & 8 & 38 & 9 & 43 & 0.10 & 0.75 \\ \text { Day I } & 7 & 33 & 8 & 38 & 0.10 & 0.75 \\ \text { Day } 7 & 3 & 17 & 6 & 30 & 0.93 & 0.33 \\ \text { Day 14 } & 3 & 17 & 4 & 21 & 0.12 & 0.73 \\ \text { Day 21 } & 3 & 21 & 2 & 13 & 0.33 & 0.56 \\ \text { Day 28 } & 3 & 23 & 1 & 7 & 1.36 & 0.24\end{array}$

\begin{tabular}{lcccccc} 
& Mean & SD & Mean & SD & $\boldsymbol{t}$ & $\boldsymbol{P}$ \\
\hline Age (years) & 47.2 & 13.0 & 47.2 & 13.3 & -0.01 & 0.99 \\
Age of onset (years) & 21.0 & 11.9 & 19.4 & 11.5 & 0.45 & 0.66 \\
Length of illness (years) & 26.4 & 12.8 & 27.6 & 13.1 & -0.30 & 0.77 \\
Length of current episode (months) & 110.0 & 152.0 & 84.9 & 118.4 & 0.59 & 0.56 \\
$\begin{array}{l}\text { Time in hospital before study } \\
\text { start (days) }\end{array}$ & 49.5 & 21.1 & 42.6 & 26.3 & 0.95 & 0.35 \\
Suicide attempts & & & & & & \\
Body mass index & 0.7 & 1.4 & 1.3 & 2.0 & -1.16 & 0.25 \\
& 29.5 & 5.8 & 31.4 & 7.3 & -0.96 & 0.34
\end{tabular}

Clinical scale ratings at baseline

$\begin{array}{lcccccc}\begin{array}{l}\text { Montgomery-Asberg } \\ \text { depression rating scale }\end{array} & 32.7 & 5.7 & 32.7 & 3.7 & 0.03 & 0.97 \\ \begin{array}{l}\text { Hamilton depression rating } \\ \text { sclit }\end{array} & 20.8 & 4.5 & 20.4 & 4.4 & 0.31 & 0.76\end{array}$
scale- 17 item
Table I Continued

\begin{tabular}{|c|c|c|c|c|c|c|}
\hline & Mean & SD & Mean & SD & $t$ & $\mathbf{P}$ \\
\hline Beck depression inventory & 26.5 & 7.6 & 27.1 & 8.9 & -0.22 & 0.83 \\
\hline Brief psychiatric rating scale (positive) & 9.5 & 1.3 & 10.0 & 1.6 & -1.05 & 0.30 \\
\hline $\begin{array}{l}\text { Clinician administered dissociative } \\
\text { states scale }\end{array}$ & 2.6 & 2.7 & 4.9 & 10.0 & -0.99 & 0.33 \\
\hline Scale for suicide ideation & 3.1 & 5.5 & 2.0 & 3.9 & 0.71 & 0.48 \\
\hline Young mania rating scale & 4.5 & 2.3 & 5.2 & 3.4 & -0.84 & 0.41 \\
\hline Medication trials lifetime & 7.7 & 4.1 & 7.1 & 3.8 & 0.47 & 0.64 \\
\hline $\begin{array}{l}\text { Maximum riluzole dose } \\
\text { (blinded) (mg/day) }\end{array}$ & 166.7 & 48.3 & 173.8 & 43.6 & -0.50 & 0.62 \\
\hline \multicolumn{7}{|l|}{ Plasma levels (ng/ml) } \\
\hline \multicolumn{7}{|l|}{ Ketamine } \\
\hline $40 \mathrm{~m}$ & 187.0 & 78.9 & 149.4 & 53.1 & 1.29 & 0.21 \\
\hline $80 \mathrm{~m}$ & 78.4 & 15.7 & 80.9 & 23.6 & -0.28 & 0.78 \\
\hline \multicolumn{7}{|l|}{ Norketamine } \\
\hline $40 \mathrm{~m}$ & 65.7 & 57.7 & 45.6 & 9.8 & 1.14 & 0.27 \\
\hline $80 \mathrm{~m}$ & 76.7 & 31.9 & 70.4 & 16.7 & 0.58 & 0.57 \\
\hline
\end{tabular}

Abbreviations: $\mathrm{ECT}$, electroconvulsive therapy; $\mathrm{MAOI}$, monoamine oxidase inhibitor; mg, milligrams; ml, milliliters; $\mathrm{ng}$, nanograms; SNRI, serotoninnorepinephrine reuptake inhibitor; SSRI, selective serotonin reuptake inhibitor: TCA, tricyclic antidepressant.
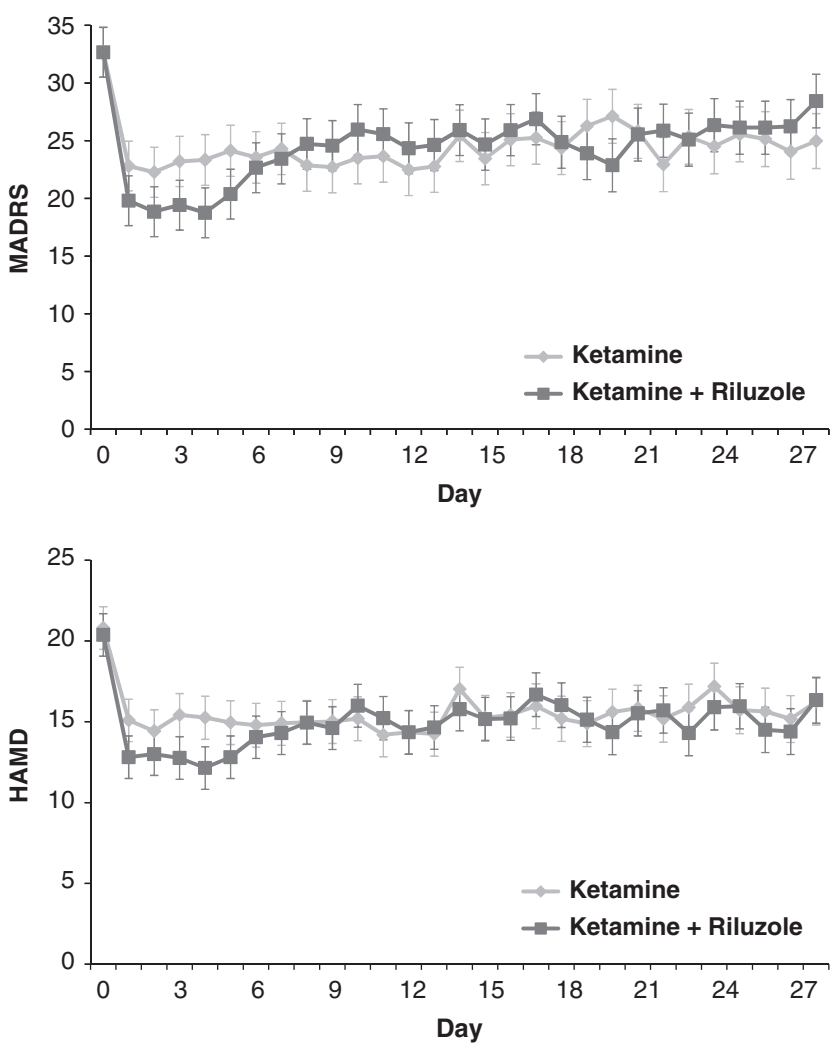

Figure 2 Mean depression score over 28 days. Hamilton Depression Rating Scale; MADRS, Montgomery Asberg Depression Rating Scale.

232, $P=0.35$ ), VAS-depression (time: $\mathrm{F}=5.34$, d.f. $=28$, 322, $P<0.001$; treatment: $\mathrm{F}=0.03$, d.f. $=1,41, P=0.87$; time $\times$ treatment: $F=0.96$, d.f. $=28,322, P=0.53)$, and 
HAM-A (time: $\mathrm{F}=27.52$, d.f. $=6,124, P<0.001$; treatment: $\mathrm{F}=1.21$, d.f. $=1,39, P=0.28$; time $\times$ treatment: $\mathrm{F}=0.40$, d.f. $=6,124, P=0.88)$. HAM-D, BDI, and HAM-A ratings improved significantly for the group as a whole from day 1 through day 28. VAS-depression ratings improved significantly for the group as a whole on all days except days 16, $18,19,24,25,27$, and 28. For secondary analyses using the CADSS, BPRS, BPRS-positive symptoms, YMRS, and SSI see Supplementary Figures 1-5.

\section{Additional Analyses}

When the analysis was limited to participants who responded to ketamine within the first $230 \mathrm{~min}$ on the day of infusion, the results were unchanged for the primary outcome measure (MADRS), showing only a significant effect for time (time: $\mathrm{F}=8.41$, d.f. $=28,177, P<0.001$; treatment group: $\mathrm{F}=0.57$, d.f. $=1,24, P=0.46$; time $\times$ treatment group: $\mathrm{F}=1.42$, d.f. $=28,177, P=0.09$ ). The biggest nonsignificant differences between the treatment groups occurred at day 4 (Cohen's $d=0.74,95 \%$ confidence interval: $0.15-1.32$ ), indicating lower scores in the ketamineriluzole group.

In all, 62\% (26/42) of patients reached response criteria at some time prior to randomization. For these responders, $27 \%(7 / 26)$ did not relapse throughout the 4-week study. Three more patients $(38 \% ; 10 / 26)$ did not relapse for at least 2 weeks, and five more $(58 \% ; 15 / 26)$ did not relapse for at least a week. Separating by group, 33\% (4/12) of the ketamine-riluzole group and $21 \%(3 / 14)$ of the ketamineplacebo group had not relapsed prior to the end of the study. One patient in the ketamine-riluzole group met relapse criteria on day 28. Kaplan-Maier survival analysis showed no significant difference between the treatment groups (log rank test, $\chi^{2}=2.50, P=0.11$; Figure 3 ). On average, patients took $13.2(\mathrm{SE}=2.2)$ days to relapse. The ketamine-riluzole group took $17.2(\mathrm{SE}=3.1)$ days and the ketamine-placebo group took 9.8 days $(\mathrm{SE}=2.8)$ to relapse.

Pearson's correlations showed that plasma ketamine and norketamine levels as well as riluzole dose did not correlate with the change in MADRS scores (see Supplementary Appendix 2).

\section{Adverse Events}

No serious adverse events occurred during the study. Consistent with previous studies, perceptual disturbances, drowsiness, confusion, elevations in blood pressure and pulse, and dizziness occurred during ketamine infusion, but resolved within $80 \mathrm{~min}$. No clinically meaningful changes in respiratory rate, arterial oxygen saturation, or ECG occurred over the course of the study.

No difference was noted in the emergence of side effects between treatment groups (see Supplementary Table 1), nor were significant changes from baseline noted between groups for complete blood counts, liver function tests, vital signs, or weight.

\section{DISCUSSION}

This study had two notable findings. First, a single dose of the NMDAR antagonist ketamine significantly improved

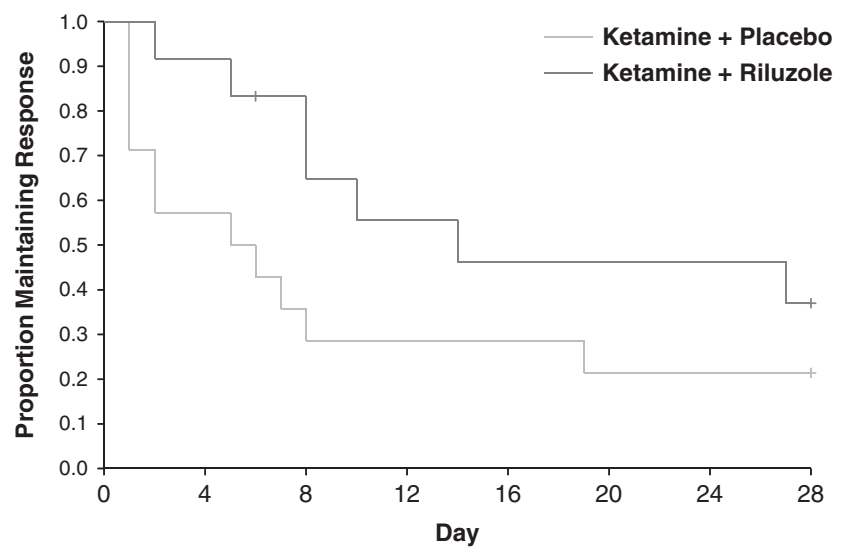

Figure 3 Survival curves for time to relapse in responders by treatment group. Response was considered a 50\% improvement from baseline on the MADRS. Relapse was considered a $<25 \%$ improvement from baseline for at least 2 consecutive days after reaching at least $50 \%$ improvement.

depressive symptoms in TRD patients over the course of 4 weeks. Second, the addition of the glutamatergic modulator riluzole did not enhance antidepressant response compared with the addition of placebo following an infusion of ketamine.

We found significant improvement compared with baseline in subjects with TRD over the course of 4 weeks following a single dose of ketamine. When both treatment groups were combined, patients scored - on average- 6.0 $(S E=1.2)$ points lower on the MADRS 4 weeks after ketamine infusion. The effect sizes for change from baseline ranged from large $(d=1.02)$ on day 2 to moderate $(d=0.46)$ on day 28 . In addition, $58 \%$ of initial responders had not relapsed at 1 week, $38 \%$ had not relapsed at 2 weeks, and $27 \%$ had not relapsed at the study end point of 4 weeks. This finding is especially remarkable, given the severity of illness of this particular patient sample.

With regard to the comparison between the ketamineriluzole and ketamine-placebo groups, consistent overlap in the pattern of response was seen across the four different depression (MADRS, HAM-D, BDI, and VAS-depression) and anxiety (HAM-A) scales. Several explanations may account for the lack of difference between the two groups. First, a moderate effect was observed following ketamine infusion that persisted throughout the study. Without a significant reduction in that initial effect, the ability to see an additional response to riluzole may have been minimized. However, a substantial level of depressive symptoms persisted throughout the study, so this seems unlikely. Second, it is hypothetically possible that ketamine's mechanism of action might itself block or mute patients' response to riluzole. Third, the patients in the ketamineriluzole group took longer to relapse than patients in the ketamine-placebo group (17.2 vs 9.8 days); although this difference was not statistically significant, it may nevertheless have been clinically meaningful.

Fourth, the dose of riluzole used, the route of administration, and the level of treatment refractoriness of this population may have made it difficult to detect an antidepressant signal. To further explore this, we conducted a post-hoc analysis on the efficacy of riluzole solely in those 
patients who had not responded to ketamine and found that riluzole had no appreciable antidepressant effects beyond placebo in this group of TRD patients. Both the considerable treatment refractoriness of the population as well as the short duration of the trial could account for this lack of efficacy. In an earlier open-label study, the antidepressant effects of riluzole were measurable within 3 weeks in a group of TRD patients (Zarate et al, 2004), but such an effect might not have persisted with a placebo control. Future controlled studies are needed to address these methodological issues and further clarify the antidepressant profile of riluzole.

Fifth, it is possible that the lack of sustained improvement with riluzole following ketamine infusion was due to riluzole's inability to maintain the neurobiological changes (ie, synaptic plasticity) necessary for capturing and sustaining the antidepressant effects of ketamine. In addition to modulating presynaptic glutamate release, several studies have shown that riluzole modifies excitatory amino-acid transporter expression and function, thereby modulating glutamate clearance and cycling (Banasr et al, 2008; Frizzo et al, 2004; Gourley et al, 2012). These additional effects, which include changes in AMPA transmission, appear to be time- and dose-dependent, thus suggesting that the timing of riluzole dosing relative to ketamine administration could be important in achieving a sustained antidepressant effect with ketamine. Finally, there may be off-site targets responsible for the antidepressant effects of ketamine that are not engaged by riluzole (eg, sigma receptors (Robson et al, 2011)).

In the present study, the largest effect size comparing treatments for a time point on the primary outcome measure was 0.35 . With this effect size and $80 \%$ power, a minimum of 130 patients would be needed per group to find a significant effect. Such a sample size is well beyond the initial sample size estimate of 34 per group. Furthermore, doubling the present sample size would offer only $35 \%$ power to detect the present effect.

Several differences between the present study and that of Mathew et al (2010) permit us to build on that previous study, as well as better characterize the course of response to ketamine over 4 weeks. Specifically, the present study had: (1) a larger sample size (42 vs 14, randomized); (2) the requirement that patients be hospitalized for 4-6 weeks before ketamine infusion and throughout the study $v s$ only $24 \mathrm{~h}$ post infusion in the study by Mathew et al (2010); (3) the requirement that patients be free of psychotropic medications for 2 weeks before infusion $v s$ in the Mathew et al (2010) study, where patients were pretreated with either lamotrigine $300 \mathrm{mg}$ p.o. or placebo immediately prior to the infusion; (4) the fact that the patients were randomized to either riluzole or placebo within $6 \mathrm{~h}$ post-infusion $v s$ after $72 \mathrm{~h}$ of sustained response in the study by Mathew et al (2010); and (5) daily ratings $v s$ biweekly ratings.

In addition, this study had several strengths. Subjects were hospitalized for an average of 46 days prior to ketamine infusion, permitting sufficient time to characterize them, document the stability of depressive symptoms during their current episode despite inpatient treatment, and monitor compliance with study medications. In addition, the study of riluzole was double-blind and randomized. All subjects had been completely free of psychotropic medica- tions for at least 2 weeks prior to infusion and randomization. Nevertheless, the relatively small sample size and the refractoriness of the patient sample limit our ability to generalize the findings to all patients with major depressive disorder. Specifically, TRD patients who have been ill for many years may have different neurobiological and pharmacological responses to both ketamine and riluzole than patients whose course of illness is shorter or less severe.

As noted previously, a dearth of effective, rapid, and sustained treatments exist for major depressive disorder. The data presented here suggest that a single 40-min infusion of ketamine was associated with rapid and potentially durable antidepressant response lasting up to 4 weeks. This finding of an ongoing antidepressant effect lasting approximately 4 weeks from a single infusion of ketamine is much longer than the length of improvement - typically less than 7 days - that has previously been reported and deserves further study. Future studies should also examine alternative strategies for the long-term maintenance of antidepressant effects of ketamine. Relevant strategies might include investigating repeat doses of ketamine, or combining ketamine treatment with electroconvulsive therapy or antidepressants. In addition, particular consideration should be given to studying other types of glutamatergic modulators such as oral NMDA antagonists or AMPA potentiators (Machado-Vieira et al, 2011). Identifying a treatment strategy that eliminates the lag of onset of antidepressant effects would have a major impact on public health.

\section{ACKNOWLEDGEMENTS}

We thank Dr Andrew Newberg and the 7SE research unit and research staff for medical support.

\section{DISCLOSURE}

This study was supported in part by the Intramural Research Program of the National Institute of Mental Health, National Institutes of Health (NIMH-NIH). The author(s) declare that, except for income received from our primary employer, no financial support or compensation has been received from any individual or corporate entity over the past 3 years for research or professional service and there are no personal financial holdings that could be perceived as constituting a potential conflict of interest. A patent application for the use of ketamine in depression has been submitted listing Drs Zarate and Manji among the inventors; they have assigned their rights on the patent to the U.S. government, but will share a percentage of any royalties that may be received by the government.

\section{REFERENCES}

aan het Rot M, Collins KA, Murrough JW, Perez AM, Reich DL, Charney DS et al (2010). Safety and efficacy of repeated-dose intravenous ketamine for treatment-resistant depression. Biol Psychiatry 67: 139-145.

Aitken RC (1969). Measurement of feelings using visual analogue scales. Proc R Soc Med 62: 989-993.

Banasr M, Chowdhury GM, Terwilliger R, Newton SS, Duman RS, Behar KL et al (2008). Glial pathology in an animal model of 
depression: reversal of stress-induced cellular, metabolic and behavioral deficits by the glutamate-modulating drug riluzole. Mol Psychiatry 15: 501-511.

Beck AT, Beamesderfer A (1974). Assessment of depression: the depression inventory. Mod Probl Pharmacopsychiatry 7: 151-169.

Beck AT, Kovacs M, Weissman A (1979). Assessment of suicidal intention: the Scale for Suicide Ideation. J Consult Clin Psychol 47: 343-352.

Berman RM, Cappiello A, Anand A, Oren DA, Heninger GR, Charney DS et al (2000). Antidepressant effects of ketamine in depressed patients. Biol Psychiatry 47: 351-354.

Bremner JD, Krystal JH, Putnam FW, Southwick SM, Marmar C, Charney DS et al (1998). Measurement of dissociative states with the Clinician-Administered Dissociative States Scale (CADSS). J Trauma Stress 11: 125-136.

Diazgranados N, Ibrahim L, Brutsche NE, Newberg A, Kronstein P, Khalife $S$ et al (2010a). A randomized add-on trial of an $\mathrm{N}$-methyl-D-aspartate antagonist in treatment-resistant bipolar depression. Arch Gen Psychiatry 67: 793-802.

Diazgranados N, Ibrahim LA, Brutsche NE, Ameli R, Henter ID, Luckenbaugh DA et al (2010b). Rapid resolution of suicidal ideation after a single infusion of an $N$-methyl-D-aspartate antagonist in patients with treatment-resistant major depressive disorder. J Clin Psychiatry 71: 1605-1611.

Du J, Suzuki K, Wei Y, Wang Y, Blumenthal R, Chen Z et al (2007). The anticonvulsants lamotrigine, riluzole, and valproate differentially regulate AMPA receptor membrane localization: relationship to clinical effects in mood disorders. Neuropsychopharmacology 32: 793-802.

First MB, Spitzer RL, Gibbon M, Williams AR (2001). Structured Clinical Interview for DSM-IV TR Axis I Disorders, Research Version, Patient Edition (SCID-I/P). New York State Psychiatric Institute, Biometrics Research: New York.

Frizzo ME, Dall'Onder LP, Dalcin KB, Souza DO (2004). Riluzole enhances glutamate uptake in rat astrocyte cultures. Cell $\mathrm{Mol}$ Neurobiol 24: 123-128.

Gourley SL, Espitia JW, Sanacora G, Taylor JR (2012). Antidepressant-like properties of oral riluzole and utility of incentive disengagement models of depression in mice. Psychopharmacology 219: 805-814.

Hamilton M (1959). The assessment of anxiety states by rating. Br J Med Psychol 32: 50-55.

Hamilton M (1960). A rating scale for depression. J Neurol Neurosurg Psychiatry 23: 56-62.

Li N, Lee B, Liu RJ, Banasr M, Dwyer JM, Iwata M et al (2010). mTOR-dependent synapse formation underlies the rapid antidepressant effects of NMDA antagonists. Science 329: 959-964.

Machado-Vieira R, Ibrahim L, Henter ID, Zarate CA (2012). Novel glutamatergic agents for major depressive disorder and bipolar disorder. Pharmacol Biochem Behav 100: 678-687.

Machado-Vieira R, Salvadore G, Luckenbaugh DA, Manji HK, Zarate Jr CA (2008). Rapid onset of antidepressant action: a new paradigm in the research and treatment of major depressive disorder. J Clin Psychiatry 69: 946-958.
Maeng S, Zarate Jr CA (2007). The role of glutamate in mood disorders: results from the ketamine in major depression study and the presumed cellular mechanism underlying its antidepressant effects. Curr Psychiatry Rep 9: 467-474.

Maeng S, Zarate Jr CA, Du J, Schloesser RJ, McCammon J, Chen G et al (2008). Cellular mechanisms underlying the antidepressant effects of ketamine: role of alpha-amino-3-hydroxy-5-methylisoxazole-4-propionic acid receptors. Biol Psychiatry 63: 349-352.

Mathew SJ, Murrough JW, aan het Rot M, Collins KA, Reich DL, Charney DS (2010). Riluzole for relapse prevention following intravenous ketamine in treatment-resistant depression: a pilot randomized, placebo-controlled continuation trial. Int J Neuropsychopharmacol 13: 71-82.

Montgomery SA, Asberg M (1979). A new depression scale designed to be sensitive to change. Br J Psychiatry 134: 382-389.

Overall JE, Gorham DR (1962). The Brief Psychiatric Rating Scale. Psychol Rep 10: 799-812.

Preskorn SH, Baker B, Kolluri S, Menniti FS, Krams M, Landen JW (2008). An innovative design to establish proof of concept of the antidepressant effects of the NR2B subunit selective $N$-methyl-Daspartate antagonist, CP-101,606, in patients with treatmentrefractory major depressive disorder. J Clin Psychopharmacol 28: 631-637.

Robson MJ, Elliott M, Seminerio MJ, Matsumoto RR (2011). Evaluation of sigma receptors in the antidepressant-like effects of ketamine in vitro and in vivo. Eur Neuropsychopharmacol e-pub ahead of print 10 September 2011.

Sackeim HA (2001). The definition and meaning of treatmentresistant depression. J Clin Psychiatry 62(Suppl 16): 10-17.

Sanacora G, Kendell SF, Levin Y, Simen AA, Fenton LR, Coric V et al (2007). Preliminary evidence of riluzole efficacy in antidepressant-treated patients with residual depressive symptoms. Biol Psychiatry 61: 822-825.

Sanacora G, Zarate CA, Krystal JH, Manji HK (2008). Targeting the glutamatergic system to develop novel, improved therapeutics for mood disorders. Nat Rev Drug Discov 7: 426-437.

Valentine GW, Mason GF, Gomez R, Fasula M, Watzl J, Pittman B et al (2011). The antidepressant effect of ketamine is not associated with changes in occipital amino acid neurotransmitter content as measured by [(1)H]-MRS. Psychiatry Res 191: 122-127.

Young RC, Biggs JT, Ziegler VE, Meyer DA (1978). A rating scale for mania: reliability, validity and sensitivity. Br J Psychiatry 133: 429-435.

Zarate Jr C, Machado-Vieira R, Henter I, Ibrahim L, Diazgranados N, Salvadore G (2010). Glutamatergic modulators: the future of treating mood disorders? Harv Rev Psychiatry 18: 293-303.

Zarate Jr CA, Payne JL, Quiroz J, Sporn J, Denicoff KK, Luckenbaugh D et al (2004). An open-label trial of riluzole in patients with treatment-resistant major depression. $A m \mathrm{~J}$ Psychiatry 161: 171-174.

Zarate Jr CA, Singh JB, Carlson PJ, Brutsche NE, Ameli R, Luckenbaugh DA et al (2006). A randomized trial of an $\mathrm{N}$ methyl-D-aspartate antagonist in treatment-resistant major depression. Arch Gen Psychiatry 63: 856-864.

Supplementary Information accompanies the paper on the Neuropsychopharmacology website (http://www.nature.com/npp) 